\title{
UMA BREVE ANÁLISE DA FEIRA AGROECOLÓGICA DO PARQUE DO SABIÁ EM UBERLÂNDIA - MG
}

\author{
Mariana Moreira Santos ${ }^{1}$; Taynara Laís Martins de Oliveira²; Maria Beatriz Junqueira \\ Bernardes $^{3}$
}

\section{RESUMO}

A agroecologia tem ganhado espaço na vida de cada vez mais pessoas, tanto para produtores quanto para consumidores, na disseminação da busca por um modo de vida ecológico e uma alimentação saudável. A cidade de Uberlândia MG recebeu uma nova Feira Agroecológica semanal, que ocorre no Parque do Sabiá. Este trabalho tem como objetivo conhecer a trama que envolve a produção e comercialização da feira que ocorre no referido parque. Para a construção dessa análise foi realizada pesquisa bibliográfica, visita à feira e análise das informações obtidas por meio da entrevista realizada. Pôde-se perceber que existe a demanda da população uberlandense por produtos agroecológicos, e os feirantes têm percebido que o maior desafio é ter espaço no mercado. Neste caso, conquistar mais consumidores se torna um trabalho intrínseco à educação ambiental.

Palavras-chave: Agroecologia; Feiras livres; Educação ambiental.

\section{A BRIEF ANALYSIS OF THE AGROECOLOGICAL FAIR OF SABIÁ PARK IN UBERLÂNDIA - MG}

\section{ABSTRACT}

Agroecology has gained space in the lives of more and more people, both for producers and consumers, in spreading the search for an ecological way of life and a healthy diet. The city of Uberlândia - MG received a new weekly Agroecological Fair, which takes place in Sabiá Park. This work aims to know the plot that involves the production and commercialization of the fair that takes place in said park. For the construction of this analysis, a bibliographical research was carried out, a visit to the fair and an analysis of the information obtained through the interview. It was possible to perceive that there is the demand of the Uberlandian population for agroecological products, and the marketers have realized that the biggest challenge is to have space in the market. In this case, conquering more consumers becomes an intrinsic job to environmental education.

1 Graduanda em Geografia. Universidade Federal de Uberlândia. E-mail: mareanams@gmail.com.

2 Graduanda em Engenharia Ambiental. Universidade Federal de Uberlândia. E-mail: taynaralais13@hotmail.com.

3 Docente do Programa de Pós-Graduação em Geografia da Universidade Federal de Uberlândia. E-mail: mariabeatrizjunqueira@gmail.com. 
Keywords: Agroecology; Free fair; Environmental education.

\title{
Introdução
}

Com o início da modernização na agricultura apenas foi privilegiado o aumento da produtividade, desprezando o agricultor e o ambiente como partes do mesmo processo de desenvolvimento, ocasionando diversos problemas sociais e ambientais.

Porém, logo surgiram os movimentos da população para agriculturas alternativas, que visam uma produção mais limpa, livre de máquinas, mais sustentáveis e sem uso de produtos químicos prejudiciais à saúde, baseando assim o princípio da agroecologia. Com a maior tomada de consciência por parte da população o número de consumidores cresceu, e aumentou também ainda mais a oferta. Segundo Assis e Aquino (2005, p.175) a prática agroecológica ainda teria muito a mostrar:

\begin{abstract}
Apesar dessa realidade, considera-se possível modificar a trajetória tecnológica, atualmente dominante na agricultura brasileira, e ampliar consideravelmente no país a produção com base em modelos agroecológicos de produção, uma vez que diversas experiências demonstram a viabilidade técnica, econômica e social desses modelos, contribuindo para o estabelecimento de um processo de desenvolvimento agrícola sustentável.
\end{abstract}

Por acreditarmos que a educação é um dos mais eficazes meios para a transformação da realidade instituída, buscamos por meio dela uma relação conjunta com a agroecologia e as práticas de feiras livre na cidade de Uberlândia- MG. Desta maneira a educação ambiental surge neste cenário para que se tenha em vista a necessidade da crescente tomada de consciência sobre a problemática ambiental pela qual é vitimado todo planeta. Segundo (CRIVELLARO, et al. 2008, p. 28):

A adoção de práticas mais amigáveis com a natureza requer
mudanças, transformações e novos comportamentos. Diante disso,
não podemos deixar de inserir a educação ambiental quando falamos
em agroecologia, pois ambas surgem da necessidade de mudanças,
adoção de novos estilos de vida que tragam melhor qualidade de
vida, conservação da biodiversidade e geração de trabalho, em um
sistema econômico mais justo.

Dentre as variações que existem no ambientalismo, Sauvé (1997) é citada no Cadernos SECAD 1 (2007) quando coloca o meio ambiente como a 
meta da educação ambiental, ou seja, a busca do aprendizado se dá com finalidade de resolver e prevenir os problemas ambientais.

A nível mundial, a chamada para a tomada de consciência da sociedade por meio da educação ambiental é assunto de conferências internacionais, como afirma Sorrentino (1998), citado por Jacobi (2003), que existe a necessidade da articulação de ações da educação ambiental que estejam baseadas em conceitos de ética e sustentabilidade, identidade cultural e diversidade, mobilização e participação, e também de práticas interdisciplinares, no documento da Conferência Internacional sobre Meio Ambiente e Sociedade, Educação e Consciência Pública para a Sustentabilidade, realizada na cidade de Tessalônica, na Grécia.

A educação ambiental vem sendo valorizada cada vez mais, como uma ação educativa que deve estar presente nas nossas vidas, unindo o conjunto de saberes, a formação de atitudes, a tomada de consciência ambiental, responsabilidade, compromisso e solidariedade, que constituem aspectos fundamentais para a formação do sujeito ecológico.

Dentro dessa abordagem sugerem-se maneiras ou formas que seria determinante para a inclusão e transformação social, segundo Duarte e Silva (2009, apud JACOBI, 2009, p. 3):

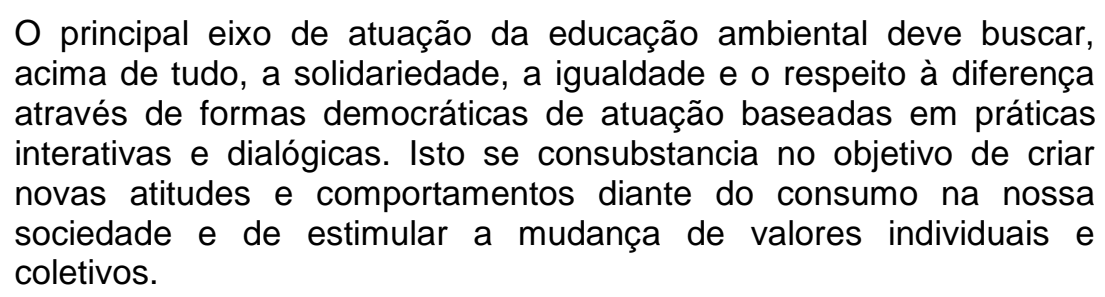

Tendo em vista esta temática abrangente da agroecologia e a educação ambiental, esta pesquisa surgiu por meio de alguns questionamentos a fim de saber como ocorre na prática esta realidade, vislumbrando como referência principal a Feira Agroecológica do Parque do Sabiá, na cidade de UberlândiaMG.

Existem muitos vendedores comercializando na feira? Quais são as motivações para realização do trabalho de feirante e produtor agroecológico? Qual a visão destes feirantes sobre a agroecologia? Quais são as dificuldades enfrentadas por esses produtores? Que tipo de alimento é comercializado nestas feiras? Existe uma demanda da sociedade para este tipo de alimento ser comercializado? 
Desta forma, o objetivo geral deste trabalho é conhecer a trama que envolve a produção e comercialização da feira que ocorre no referido parque. Para a realização desta amostra será feita a realização de visitas à feira para observação dos feirantes e dos produtos comercializados; o registro das informações observadas; a elaboração de tabelas com os dados obtidos; e a revisão bibliográfica sobre o tema.

A justificativa para a realização deste artigo se dá no sentido de conhecer e apresentar esta nova realidade que a cidade de Uberlândia vive, a fim de documentar como a feira agroecológica impacta a cidade, sendo ela a população que consome, e o olhar do produtor e feirante. A reflexão sobre a disseminação dessas informações dá lugar à busca por novos públicos para esta feira através da divulgação do conhecimento agroecológico e da educação ambiental.

Este artigo se vincula também à pesquisa das autoras sobre agroecologia na cidade de Uberlândia, que está sendo desenvolvida na graduação em Geografia pelo recorte do Trabalho Final de Graduação - TFG em um estudo sobre feiras agroecológicas em Uberlândia, e também na Engenharia Ambiental por meio de uma iniciação cientifica - IC - em estudo sobre um assentamento que possui cultivos agroecológicos, ambas pela Universidade Federal de Uberlândia.

Neste artigo será abordado, num primeiro momento, o conceito de agroecologia e o que ela representa para a sociedade e para o meio ambiente, assim como as feiras livres. Em seguida, será feita a apresentação da Feira Agroecológica do Parque do Sabiá em Uberlândia-MG, e os resultados obtidos através de visitas nesta feira. Por fim, uma reflexão sobre a relação entre a educação ambiental e as feiras agroecológicas.

\section{Agroecologia}

A agricultura pode ser entendida como a arte de cultivar os campos, utilizando recursos naturais indispensáveis como o ar, o sol, a água e o solo. Durante milhares de anos foi realizada a agricultura sem o uso de agrotóxicos, com o emprego de rotações de cultura associadas a pousio e também a criação de animais. Essas práticas foram abandonadas a partir da 
industrialização da agricultura, no período chamado de Revolução Verde, momento em que o produtor perde a sua autonomia.

O incentivo à produção mecanizada em larga escala com a utilização de insumos químicos e sementes modificadas predominou durante muitos anos, porém o conhecimento acerca da agricultura tradicional permaneceu e está sendo resgatado por produtores que não escolheram ou buscam abandonar esta forma de cultivo. Há quem opte por produzir com qualidade, e não apenas visando a quantidade.

Surge neste contexto a agroecologia, que advém de uma evolução das práticas ecológicas na agricultura pelo mundo, como a agricultura biodinâmica, a agricultura orgânica, a agricultura biológica, a agricultura natural, a permacultura e os sistemas agroflorestais.

Define-se também como o estudo da agricultura a partir de uma visão ecológica, sustentável e menos agressiva ao meio ambiente. Trata-se de um tipo de prática agrícola que prioriza a utilização dos recursos naturais com mais consciência, respeitando e mantendo o que a natureza oferece, promovendo melhores condições econômicas para agricultores.

É também uma alternativa que pretende reduzir os danos causados à biodiversidade e à sociedade como um todo, pela prática tradicional de agricultura e pelo emprego dos transgênicos, dos fertilizantes industriais e dos agrotóxicos. Esta prática é conhecida por desenvolver produtos "verdes", sustentáveis, "limpos" e orgânicos, livres de resíduos químicos, trazendo assim uma ideia de "nova agricultura".

Fundamentada na valorização da diversidade cultural e biológica, a prática agroecológica busca conservar e resgatar as variedades crioulas e o conhecimento tradicional das populações locais (EMBRAPA, 2006). Portanto, diferentemente da forma de difusão empregada na agricultura convencional, promovida por meio de "pacotes tecnológicos", o conhecimento agroecológico se expande por meio da socialização e da troca de saberes entre as comunidades, e se estabelece de forma participativa (CAPORAL e COSTABEBER, 2004).

Após a promulgação da Lei nº 10.831 de 2003, que dispôs sobre a agricultura orgânica, o Brasil instituiu uma política mais ampla, visando à promoção dos sistemas de produção abarcados por essa lei e oficializando 
assim o fomento à transição agroecológica e à produção orgânica e de base ecológica como uma estratégia voltada ao desenvolvimento rural sustentável.

Por este motivo, nos parece importante reforçar a noção de agroecologia que vem respaldando o processo de transição agroecológica em curso com seu caráter ecossocial. Segundo Caporal e Costabeber (2002):

\begin{abstract}
$\mathrm{Na}$ prática e teoricamente, a Agroecologia precisa ser entendida como um enfoque científico, uma ciência ou um conjunto de conhecimentos que nos ajuda tanto para a análise crítica da agricultura convencional (no sentido da compreensão das razões da insustentabilidade da agricultura da Revolução Verde), como também para orientar o correto redesenho e o adequado manejo de agroecossistemas, na perspectiva da sustentabilidade.
\end{abstract}

É importante perceber que a agroecologia serve como uma orientação básica para as experiências de agricultura ecológica, e que o principal sentido desta ferramenta é a aplicação dessas práticas numa realidade local específica, em suas próprias condições, cumprindo assim a sua função como referencial teórico. (EMBRAPA, 2006).

Dessa forma, a agroecologia pode e deve ser vista como uma ferramenta também da educação ambiental, quando é usada como agente conscientizador que desenvolva o pensamento crítico nas pessoas acerca da produção e consumo consciente. A população, ao localizar sua função na cadeia produtiva, poderá perceber e reconstruir os valores que acredita, contribuindo assim para uma nova visão da realidade, que pode ser positiva para o fortalecimento da agroecologia como prática social. (ROCHA, 2014)

A produção agroecológica tem como base, portanto, o resgate e a valorização dos conhecimentos tradicionais acerca da agricultura, aproveitando ao máximo a eficiência energética do próprio ecossistema, buscando sempre a biodiversidade, e resgatando também com a cultura tradicional as sementes crioulas, que têm sido preservadas e cultivadas em bancos de sementes por diversos agricultores tradicionais.

É de primordial importância, também, a prática de cadeias econômicas curtas, ou seja, produção e venda local, sem o deslocamento do produto em grandes distâncias, considerando assim o balanço energético de todo o ciclo de produção. Desta maneira, é possível mensurar o gasto com a produção e com a distribuição, e os desperdícios são reduzidos pelo fato de o alimento 
fresco não ter que ser submetido à processos longos de transporte. O produtor local é valorizado e o alimento é consumido em sua maior vitalidade.

Uma vez que o produtor rural decide por cultivar agroecologicamente, os primeiros passos são a observação e o estudo do ambiente que será cultivado, para que seja feito um planejamento para o uso de tecnologias coerentes, especializadas de acordo com as condições daquele lugar. Há de se considerar a otimização da produção, adaptando-se à lógica biológica do ecossistema, que, ao aproveitar ao máximo os recursos naturais disponíveis, se obtenha um sistema agrícola mais eficiente no sentido energético.

Em qualquer situação, é essencial que se prepare o solo, ou seja, fornecer o que as sementes irão necessitar para se desenvolver, e neste processo a eficiência é gradativa e dá bons resultados a longo prazo. Para a nutrição do solo pode ser usada biomassa, adubação verde, e material orgânico para decomposição, considerando que naquele solo haverá os organismos necessários para um ciclo completo, como fungos e bactérias. A cobertura do solo também é primordial pelo fato de ser um agente protetor deste solo, da ação do sol e da chuva, e capaz de potencializar o armazenamento de água no solo, se for o caso de um ambiente que necessite disso.

A partir destes princípios básicos, a escolha das espécies que serão cultivadas é também baseada no local de cultivo, do tipo de solo e do clima. Deve-se buscar o cultivo de espécies de diferentes safras, para que ocorra variedade de alimentos para consumo o ano todo, e ter consciência do tempo destas espécies, que acompanha o ciclo da natureza, sem ter pressa ou desejar uma espécie que não é daquela época do ano, ou daquele tipo de clima, por exemplo. Tudo isso será muito relevante para uma produção eficaz e equilibrada, onde o agroecossistema esteja em sintonia com o ciclo natural da terra.

\section{Feiras Livres}

Historicamente, as feiras livres remetem à uma prática milenar, onde os produtores se reuniam num local com grande fluxo de pessoas, a fim de vender suas mercadorias. Dessa forma, as feiras livres são ferramentas comerciais utilizadas pelas civilizações ao longo dos séculos, e que sobrevivem mesmo 
com o avanço da industrialização e o surgimento dos supermercados.

No caso das feiras de alimentos, é notável a proximidade que o consumidor tem com o produtor, a procedência do alimento que está sendo oferecido, a qualidade deste alimento, dentre outros fatores. Estes são pontos que favorecem a permanência das feiras nas práticas sociais, pois além de sua função econômica, existe também sua função social e cultural.

Observa-se a partir da feira o elo entre o campo e a cidade de forma mais intensa, onde o produtor apresenta a sua oferta diretamente de sua origem para o consumidor. Em sua atividade de venda também ocorrem outras trocas além de produto e pagamento, sendo elas as trocas de saberes, orientações de como preparar o alimento, com receitas, dicas, e várias alternativas que são heranças culturais sendo passadas para novas famílias.

\begin{abstract}
As feiras livres constituem-se de uma intrincada teia de relações que configuram um diversificado conjunto de ocupações, fluxos, mercadorias e relações sociais, caracterizando-se primordialmente como uma atividade de trabalho informal essencialmente familiar, onde os envolvidos na operacionalização são geralmente membros da família, gerando por sua vez uma grande demanda de serviços diretos $e$ indiretos como transporte, insumos, embalagens $e$ atendentes. (GODOY e ANJOS, 2007, p. 364).
\end{abstract}

Segundo Ricotto (2002, apud GODOY e ANJOS, 2007), as feiras livres se mostram como um fenômeno social que, a partir disso, é possível construir uma sociedade diferente, com base democrática autêntica, onde os membros da feira tenham autonomia.

No Brasil a prática das feiras ocorre desde a sua colonização, constituindo sua importância econômica e cultural através dos séculos. São comercializados diversos tipos de mercadorias, e no quesito alimentar são produtos oriundos de agricultura familiar, em pequena escala, como frutas, legumes, hortaliças, cereais, e produtos artesanais feitos pelos próprios produtores, como queijos, doces, conservas, farinhas, dentre outras variedades. (JARDINE, 2017).

Dentre as várias categorias de feiras existentes, para este artigo se destaca a Feira Agroecológica, que tem como base a agroecologia. Os produtos comercializados nestas feiras são resultado de uma agricultura ecológica, que não utiliza agrotóxicos, e produz com insumos naturais e orgânicos, respeitando a natureza e utilizando-se dela a favor da produção. 
Em geral, as pessoas que buscam alimentos neste tipo de feira têm um perfil similar, no qual procuram um estilo de vida mais natural e socialmente justo, pois nas feiras agroecológicas são encontrados alimentos livres de produtos químicos nocivos e, de outro lado, também trabalhadores familiares que vendem ali o fruto também deste estilo de vida em equilíbrio com a natureza, e sustentam suas famílias desta forma.

É uma oportunidade de trabalho e renda para os feirantes, oferecendo através do alimento uma visão holística da relação entre a sociedade e a natureza. Um dos grandes desafios que estão interligados à popularização das feiras agroecológicas é a educação ambiental, ferramenta que pode e deve ser utilizada para a divulgação e conscientização da população à respeito desta nova relação com a natureza, mostrando ser possível produzir alimentos saudáveis livres de agrotóxicos e de forma ecológica, e através disso entender os motivos de não contribuir com a produção convencional de alimentos.

\section{Feira Agroecológica do Parque do Sabiá}

A Feira Agroecológica do Parque do Sabiá em Uberlândia-MG está acontecendo desde o mês junho de 2018, por iniciativa da prefeitura da cidade, e contou em sua inauguração com cerca de 15 vendedores distribuídos em 7 bancas. A partir de uma visita à esta feira foram feitas algumas observações em diálogos com os feirantes presentes. Todos os feirantes estão participando pela primeira vez desta feira, pois é a primeira vez a ser realizada, porém todos participam de outras feiras na cidade. Em todas as bancas os produtos são cultivados pelos próprios vendedores de forma agroecológica.

Todos os feirantes afirmam que os produtos agroecológicos são muito bem aceitos e as pessoas gostam e se interessam, procuram muito, porém precisa ser mais divulgado, para que mais pessoas tenham acesso a esses alimentos.

Em geral, todos vendem bastante na feira e são muito procurados, a demanda é grande. A maior dificuldade, segundo eles, é ter lugares seguros e fixos para vender; em três bancas há produtores que estão no início da transição agroecológica, portanto sua dificuldade no momento é expandir a sua produção para atender a demanda.

Um dos feirantes afirmou que gostaria de expandir a sua produção, mas 
não o faz para não perder alimentos por falta de oportunidade de vendas. Dos feirantes entrevistados, cinco trabalham e vivem da produção e vendas da agroecologia, e se dedicam apenas à esta profissão, seja vendendo em feiras na cidade, ou em uma loja própria, porém dois deles ainda necessitam de realizar outro tipo de trabalho fora do campo para complementar a sua renda e de sua família.

Um dos grupos de feirantes foi convidado para trabalhar num projeto de agroecologia da prefeitura, mas anteriormente já estavam vinculados no fornecimento de alimentos para a merenda escolar na prefeitura (não foi especificado na conversa se estes alimentos são agroecológicos). Eles gostaram da agroecologia e resolveram seguir este caminho que antes não conheciam.

Nesta feira há vários membros do Movimento Sem Terra, e também muitas pessoas que não fazem parte dele, e que se interessam por transformar a forma de viver, de produzir alimentos, de comer, buscando aproximar-se da natureza como um todo, e a grande maioria é contra o agronegócio. Os feirantes de modo geral praticam a agroecologia por saúde, por amor e pela consciência ambiental e alimentar.

Segundo um dos vendedores que estava comercializando seus produtos, a qualidade de vida que se tem na produção agroecológica é benéfica tanto para o produtor quanto para o consumidor, no que diz respeito ao uso de venenos e agrotóxicos.

Um dos feirantes contou que começou a sua produção agroecológica por necessidade financeira, pois alegou não conseguir fazer render a sua produção convencional. Ele gastava muito com agrotóxicos e as plantas não ficavam saudáveis, porém aprendeu com seu pai métodos inseticidas naturais e viu uma oportunidade de produzir mais gastando menos. No decorrer do aprendizado, percebeu que agroecologia vai além do lado financeiro, e aprende a cada dia os seus benefícios.

Em uma média geral, os feirantes estão trabalhando com agroecologia há pouco tempo, visto que dentre os mais recentes há bancas com produção de 5 meses, 7 meses e 8 meses, e das bancas que já fizeram a transição agroecológica há uma com produção de 2 anos e duas bancas com produção de 3 anos. 
Dentre as dificuldades que estes vendedores elencaram, eles dizem que muitas pessoas querem produtos agroecológicos e não sabem onde comprar, também disseram que produzem ainda pouco, e tem muita demanda. A grande maioria gostaria que tivesse mais oportunidades de venda, porque tem uma clientela, porém há procura e gostaria de expandir sua produção: se não tiver onde vender ela vai perder a produção - é possível expandir.

Tabela 1: Itens Disponíveis nas Bancas

\begin{tabular}{|c|c|}
\hline Produto & Quantidade de Bancas \\
\hline Couve & 5 \\
\hline Espinafre & 5 \\
\hline Limão & 5 \\
\hline Salsinha & 5 \\
\hline Alface & 4 \\
\hline Tomate-cereja & 4 \\
\hline Abacate & 3 \\
\hline Banana & 3 \\
\hline Brócolis & 3 \\
\hline Cebolinha & 3 \\
\hline Erva Cidreira & 3 \\
\hline Mamão & 3 \\
\hline Mandioca & 3 \\
\hline Pimenta & 3 \\
\hline Quiabo & 3 \\
\hline Abóbora & 2 \\
\hline Abobrinha & 2 \\
\hline Beldroega & 2 \\
\hline Hibisco & 2 \\
\hline Mexerica & 2 \\
\hline Rúcula & 2 \\
\hline
\end{tabular}

Fonte: Elaborado pelas autoras (2018)

Dentre os produtos comercializados, nota-se que há alguns itens que estão mais presentes em todas as bancas, como a couve, a salsinha, o limão, o espinafre, a alface, o tomate-cereja. Também abacate, banana, brócolis, cebolinha, erva-cidreira, mamão, mandioca, pimenta, quiabo, abóbora, abobrinha, beldroega, hibisco, mexerica e rúcula.

Encontra-se também em algumas bancas alecrim, alho-poró, batata 
doce, berinjela, beterraba, biscoitos, bucha, chuchu, coco, coentro, colorau, cúrcuma, doces, hortelã, inhame, jiló, jurubeba, laranja, manjericão, maracujá, mel, mostarda, mudas de plantas, nirá, ora-pro-nóbis, palmito, pão, pimentão, repolho e urucum. A predominância desses itens pode ser melhor observada através das imagens abaixo:

Figura 1: Alguns dos itens mais presentes em bancas de produtores que ainda estão no início da transição agroecológica.

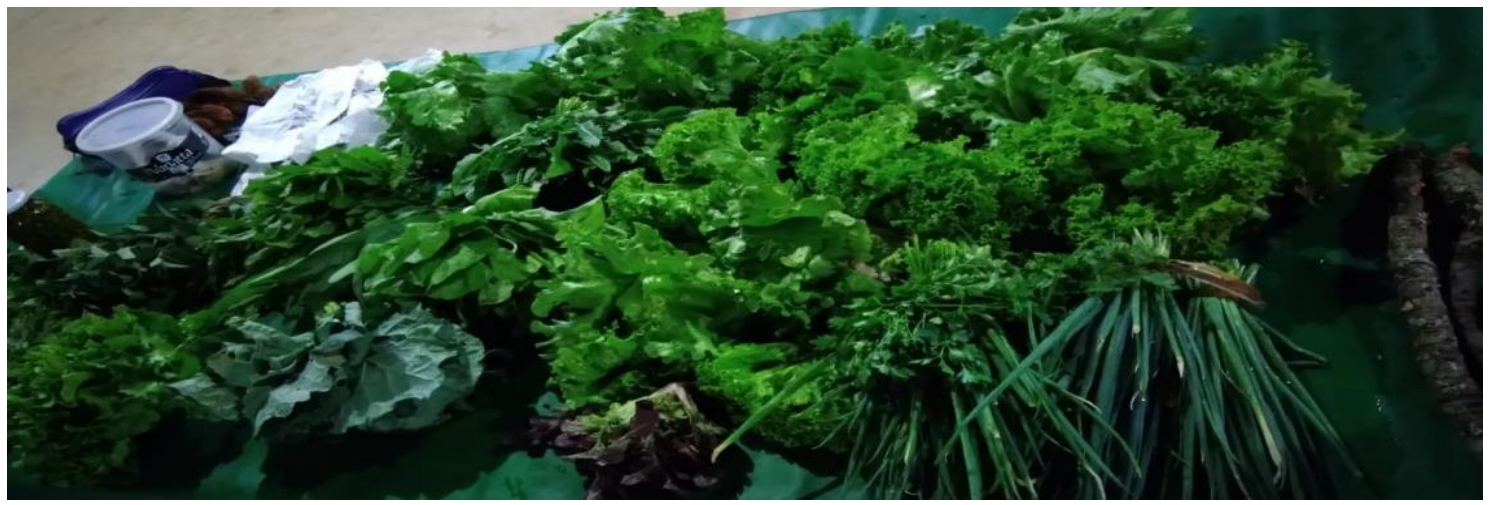

Fonte: (SANTOS e OLIVEIRA, 2018).

Figuras 2 e 3: Outros produtos com predominância nas bancas.
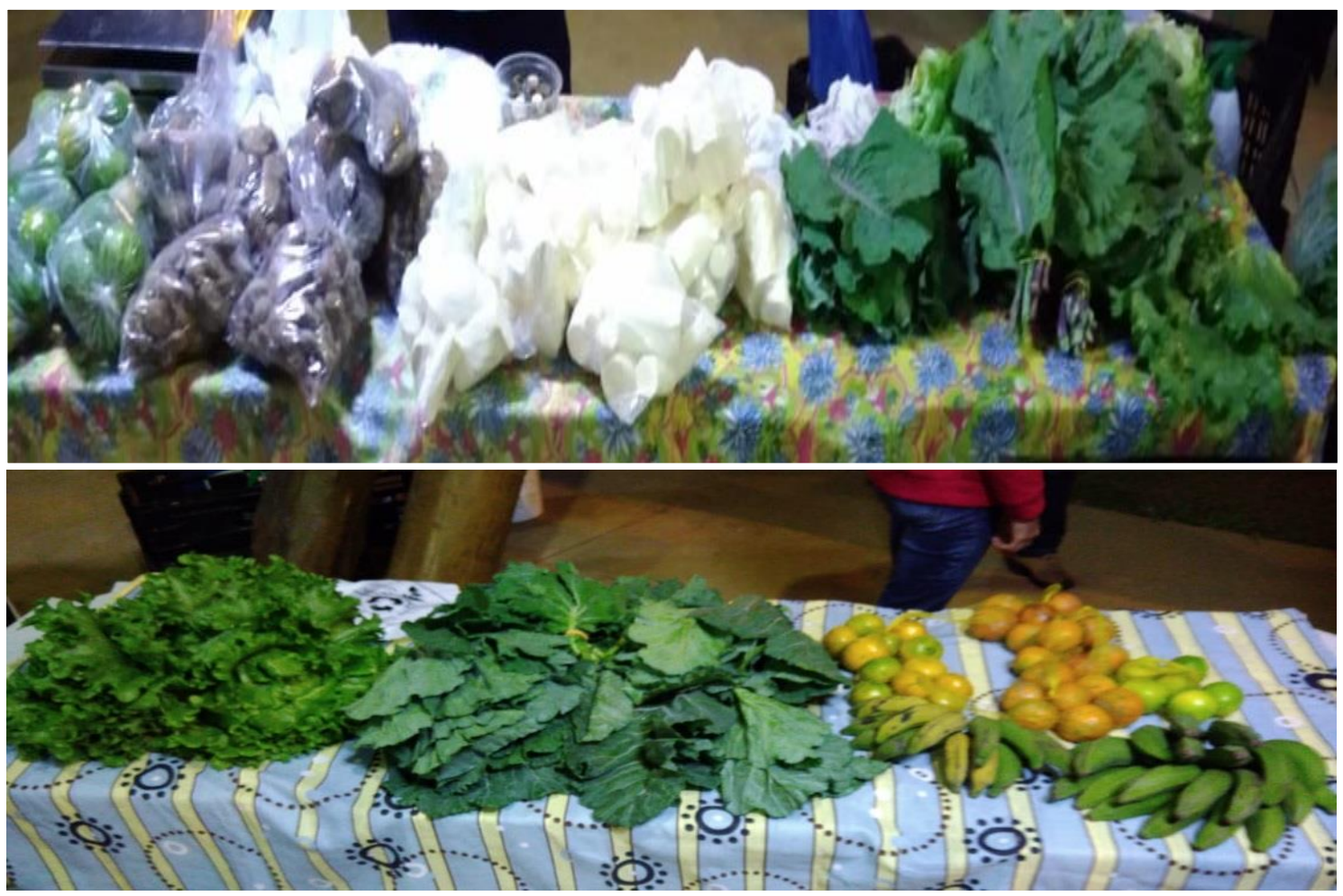

Fonte: (SANTOS e OLIVEIRA, 2018).

Há uma variedade muito grande de vegetais, bem distribuídas pelas bancas, e em grandes quantidades. O preço dos produtos também se mostrou 
justo e parece compensar a compra, lembrando que os itens vendidos nas feiras são orgânicos e totalmente livres de produtos químicos, o que exige um preço diferente dos produtos vendidos em supermercados e sacolões, que em alguns casos fazem uso de agrotóxicos.

Em pesquisa realizada em visita à feira em agosto de 2018, constatouse algumas diferenças da situação atual em comparação com o primeiro dia da feira. Havia um menor movimento de consumidores e alguns feirantes não estavam presentes. Outros novos feirantes que não participaram da inauguração também estavam presentes. Em geral os produtos ofertados eram os mesmos, com a novidade de uma banca de cosméticos, e outra banca de produtos veganos como patês, pães e tortas.

Os feirantes que estavam vendendo comentaram sobre os efeitos da estação nas compras, seja no volume de consumidores ou nos produtos escolhidos. Eles afirmam que no inverno as pessoas não têm muita disposição para sair de casa à noite, e, também, quando procuram os vegetais, preferem itens para fazer sopas, comprando menor quantidade de itens para salada, por exemplo.

Uma das feirantes que está participando da feira desde a primeira semana contou que muitas pessoas passam pela banca, gostam dos produtos, porém reclamam do preço e fazem comparações, afirmando que nos grandes mercados o preço é menor. Esta feirante diz que sempre tenta explicar sobre a diferença entre o vegetal que ela produz e o vegetal que é vendido no mercado, para que seu cliente possa compreender os benefícios de se comprar na feira. Isso mostra um trabalho de educação ambiental feito pelos feirantes.

Um outro feirante contou que não estava presente na inauguração da feira, porém participa desde a segunda semana, e falou sobre a sua produção de tomates. Disse um pouco sobre ter paciência com sua plantação, que aos poucos ela vai produzir mais, e cada vez aumentando, assim como a feira tem esse destino.

Situada em um local de grande arborização, um lago e uma pista de corrida, o Parque do Sabiá recebe todos os dias pessoas que estão em busca de um contato com a natureza e se preocupam com sua saúde praticando exercícios físicos. Pensando neste sentido, os feirantes consideraram que seria 
um bom local para a divulgação dos produtos agroecológicos, pois acreditam que essas pessoas, que ainda não conhecem esta alternativa de mercado, pudessem se identificar com esta nova possibilidade.

Isso vêm ocorrendo de forma gradativa, contam os feirantes. Muitas pessoas chegam na feira depois de sua corrida, são surpreendidas, mas quase sempre dizem que não levaram dinheiro, e na próxima semana voltam para realizar suas compras.

Neste momento, depois de dois meses de feira, os produtores acreditam que o objetivo principal de seu trabalho seja a divulgação da própria feira, que pensam ainda ser muito baixa. Através de placas de sinalização no próprio parque, ou até mesmo outdoors pela cidade possam trazer um amplo conhecimento da existência da feira pelos moradores da cidade, e assim alavancar um crescimento da feira agroecológica e de cada vez mais consumidores conscientes.

\section{Considerações Finais}

A agroecologia é uma importante prática de perspectiva ecológica, pois por meio das feiras agroecológicas, da produção agrícola familiar, da agricultura sustentável, principalmente na educação ambiental e na relação das pessoas com o meio ambiente em que vivem. Por meio das entrevistas na Feira Agroecológica do Parque do Sabiá pôde-se concluir que tanto para o agricultor e feirante quanto para o consumidor, seja ele ambientalista ou não, a feira pode representar uma oportunidade de mudança, de novas perspectivas, de alternativa positiva para o meio ambiente e para a sociedade.

O simples fato de adquirir vegetais frescos e livres de venenos direto das pessoas que o cultivaram, e ter essa disponibilidade semanalmente, já é um caminho percorrido rumo à um futuro possível, para muitos utópico e ideológico, porém se mostra real. Por meio do hábito de ir à feira agroecológica semanalmente, ou que seja quinzenalmente, as pessoas são capazes de desenvolver cada vez mais a consciência ambiental necessária para não abandonar esta prática, e desta forma contribuir também no trabalho de educação ambiental pela sua própria vivência e atitude.

E é nesse sentido que acreditamos ser necessário a potencialização das 
estratégias de educação ambiental vinculados a agroecologia, para 0 crescimento das feiras livres agroecológicas, podendo proporcionar uma visão de conservação dos recursos naturais e desenvolvimento na perspectiva agroecológica. Constatamos assim, que a educação ambiental e a agroecologia são hoje instrumentos efetivos e necessários para sensibilização das pessoas, que permitem a criação e aplicação de práticas sustentáveis de contato com a natureza.

Deste modo agroecologia está extremamente interligada com a educação ambiental, e vice-versa, e o resultado dessa união se reflete no crescimento das feiras agroecológicas, a nível local pela cidade de Uberlândia, e este cenário se mostra presente em cada vez mais cidades pelo mundo. $O$ grande desafio é a conquista deste espaço e a sua consolidação.

\section{Referências}

ASSIS, Renato Linhares de; AQUINO, Adriana Marta de. Agroecologia princípios e técnicas para uma agricultura orgânica sustentável. Embrapa. Brasília-DF, 2005.

CAPORAL, Francisco Roberto; COSTABEBER, José Antônio. Agroecologia: enfoque científico e estratégico. Agroecologia e Desenvolvimento Rural Sustentável, v.3, n.2, p.13-16, abr./mai. 2002

CAPORAL, Francisco Roberto; COSTABEBER, José Antônio. Agroecologia e extensão rural: contribuições para a promoção do desenvolvimento rural sustentável. Brasília: MDA; SAF; DATER-IICA, 2004.

CRIVELLARO, Carla Valeria Leonini, et al. Núcleo de Educação e Monitoramento Ambiental, Agroecologia: um caminho amigável de conservação da natureza e valorização da vida. Rio Grande, p. 28, 2008.

DUARTE. Rômulo Fredson; SILVA. Humberto Pereira da. A Agroecologia e Educação Ambiental como metodologia pedagógica para alunos do ensino básico e fundamental: Caso da Escola Municipal Professora Eunice Carneiro Montes Claros, MG. Revista EA. 2009.

EMBRAPA - Empresa Brasileira de Pesquisa. Marco referencial em agroecologia. Brasília: Embrapa, 2006.

GODOY, Wilson Itamar; ANJOS, Flávio Sacco dos. A importância das feiras livres ecológicas: um espaço de trocas e saberes da economia local. Revista Brasileira de Agroecologia, v. 2, n. 1, mai 2007. ISSN 1980-9735. Disponível em:

http://revistas.abaagroecologia.org.br/index.php/rbagroecologia/article/view/6312. Acesso em: 07 ago. 2018. 
GODOY, Wilson Itamar. O perfil dos feirantes ecológicos de Pelotas-RS. Revista Brasileira de Agroecologia, v. 2, n. 1, mai 2007. ISSN 1980-9735. Disponível em: http://revistas.abaagroecologia.org.br/index.php/rbagroecologia/article/view/6580. Acesso em: 05 ago. 2018.

JACOBI, Pedro. Educação ambiental, cidadania e sustentabilidade. Cadernos de Pesquisa. [Online]. 2003, n.118, pp.189-206. ISSN 0100-1574. Disponível em: http://dx.doi.org/10.1590/S0100-15742003000100008. Acesso em: 7 ago 2018.

JARDINE, Francisco Assis Miguel. As feiras livres na cidade de UberlândiaMG: Aspectos Territoriais, Sociais e Ambientais. 2017. 31 f. TCC (Graduação) Curso de Gestão Ambiental, Universidade Federal de Uberlândia, Uberlândia, 2017.

Ricardo Henriques (Org.). Educação Ambiental: aprendizes de sustentabilidade. Brasília-df: Ministério da Educação, 2007. Disponível em: http://portal.mec.gov.br/dmdocuments/publicacao2.pdf. Acesso em: 6 ago. 2018.

ROCHA, Marilene Simões da. Educação Ambiental e Agroecologia na Agricultura Familiar: Uma Contribuição para o Desenvolvimento Sustentável no Território de Irecê-BA. 2014. 211 f. Dissertação (Mestrado) - Programa de Pós-graduação em Educação e Contemporaneidade, Universidade do Estado da Bahia, Salvador, 2014. 